\title{
Reconstructing changes in the meridional overturning circulation using sedimentary ${ }^{231} \mathrm{~Pa} /{ }^{230}$ Th ratios
}

Jeanne Gherardi ${ }^{1}$, J.F. McManus ${ }^{2}$, R. Francois ${ }^{3}$ and L. Labeyrie ${ }^{4}$

'Bjerknes Centre For Climate Research, Bergen, Norway; jeanne.scao@bjerknes.uib.no;

${ }^{2}$ Department of Geology and Geophysics, Woods Hole Oceanographic Institution, USA; ${ }^{2}$ Department of Earth and Ocean Sciences, University of British Columbia, Vancouver, Canada; ${ }^{4}$ Department of Physics, University Institute of France, Gif sur Yvette, France

\section{Reconstructing ocean circulation}

The robust evidence from the nutrientproxies $\delta^{13} \mathrm{C}$ (Boyle and Keigwin, 1987; Sarnthein et al., 1994) and Cd/Ca (Marchitto and Broecker, 2006) that the water masses distribution of the ice age Atlantic Ocean was markedly different from modern observations is one of the major contributions of the field of paleoceanography to our understanding of past climate changes. These water masses are related to the Atlantic Meridional Overturning Circulation (AMOC), which plays an important role in oceanic heat transport. One goal for building upon this foundation is to develop a better understanding of past changes in the rate of the $A M O C$ and its potential role in abrupt climate change, using sedimentary proxies that are more directly influenced by circulation dynamics.

\section{${ }^{231} \mathrm{~Pa} /{ }^{230} \mathrm{Th}$ as a dynamic proxy}

We have been developing the ${ }^{231} \mathrm{~Pa} /{ }^{230} \mathrm{Th}$ circulation proxy in order to reconstruct the history of AMOC variability. This method takes advantage of the contrasting chemical behavior of ${ }^{231} \mathrm{~Pa}$ and ${ }^{230} \mathrm{Th}$ in the water column. Both nuclides are produced at a constant production ratio of 0.093 from the radioactive decay of dissolved uranium in the ocean (Turekian and Chan, 1971), and are rapidly removed from seawater by adsorption on settling particles. ${ }^{231} \mathrm{~Pa}$ is less rapidly removed than ${ }^{230} \mathrm{Th}$ and has a residence time ( $100-200 \mathrm{yr})$ approaching the transit time of deepwater in the Atlantic basin (Broecker, 1979). As a result, $\sim 50 \%$ of the ${ }^{231} \mathrm{~Pa}$ produced in Atlantic water today is exported with the North Atlantic Deep Water (NADW) into the Southern Ocean instead of being removed into the Atlantic sediments ( $Y u$ et al., 1996). On the other hand, ${ }^{230} \mathrm{Th}$ has a shorter residence time ( 20-40 yr), limiting redistribution by horizontal transport in the water column. For a given scavenging rate, lower rates of $A M O C$ in the past would result in comparatively less ${ }^{231} \mathrm{~Pa}$ export from the Atlantic and in higher sedimentary ${ }^{231} \mathrm{~Pa} /{ }^{230} \mathrm{Th}$, reaching a maximum of 0.093 for a total AMOC cessation. In the Atlantic, the production ratio may also be reached when the water mass residence time equals or exceeds 3 times the
${ }^{231} \mathrm{~Pa}$ residence time in the water column ( $\geq$ 500-600 yr). This has been calculated as in Yu et al. (1996), using the estimated modern scavenging rate (Fig. 2B). The validity of this tool as a tracer of AMOC rate has recently been supported by modeling experiments (Marchal et al., 2000; Siddall et al., 2007).

\section{Glacial-Deglacial-Holocene reconstructions}

Our methods include the production and comparison of detailed time series at different locations and water depths in the
North Atlantic basin in order to differentiate the water masses involved in AMOC because sedimentary ${ }^{231} \mathrm{~Pa} /{ }^{230} \mathrm{Th}$ integrates the circulation vigor over the overlying water column. This affords a fuller perspective on changes in AMOC associated with the dramatic climate changes since the Last Glacial Maximum (LGM) 21 $\operatorname{kyr} \mathrm{BP}( \pm 3 \mathrm{kyrs})$. Although this is a work in progress, the existing records provide new insights regarding the history of AMOC. So far, five cores have been analyzed at high resolution, providing information on past changes in the rate of $\mathrm{AMOC}$ between

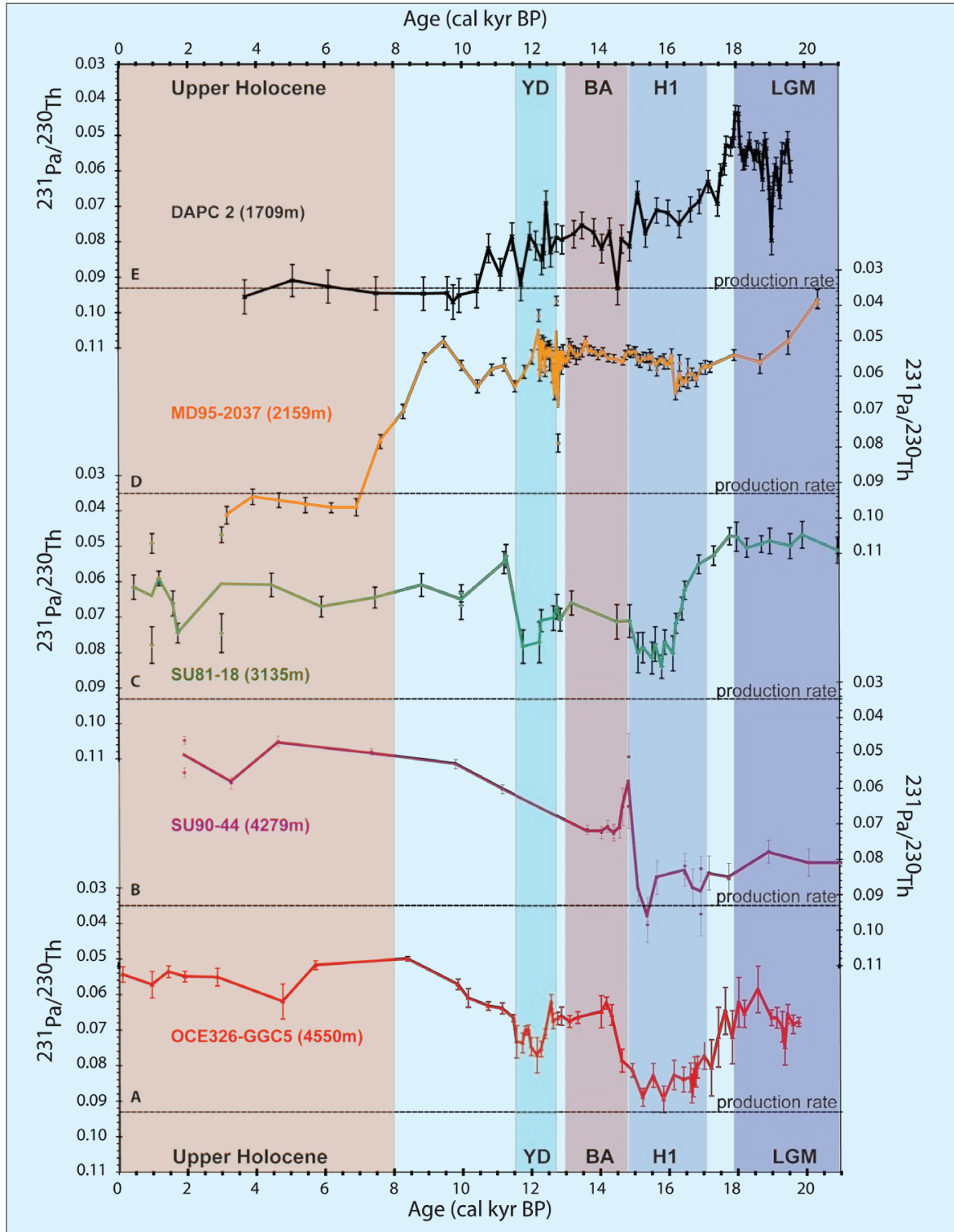

Figure 1: Sedimentary ${ }^{231} \mathrm{~Pa}$ /230Th signals; $\boldsymbol{A}$ ) core GGC5 (red) (McManus et al., 2004); $\boldsymbol{B}$ ) core SU90-44 (purple) (Gherardi et al., submitted); C) core SU81-18 (green) (Gherardi et al., 2005); D) core MD95-2037 (orange) (Gherardi et al., submitted); and E) core DAPC2 (black) (Hall et al., 2006). The ${ }^{231} \mathrm{~Pa}{ }^{230}$ Th scale is inverted. Dashed lines indicate the production ratio (0.093). Standard errors are shown as 20. YD = Younger Dryas, BA=Bølling Allerød, $H 1=$ Heinrich event 1, LGM = Last Glacial Maximum. 
$1700 \mathrm{~m}$ and $4550 \mathrm{~m}$ depth (McManus et al., 2004; Gherardi et al., 2005; Hall et al., 2006; Gherardi et al., submitted) (Fig. 1).

Since the scavenging rates and fractionation of both isotopes can be altered by particle fluxes and composition changes, it is likely that biogenic opal and productivity are not affecting the ${ }^{231} \mathrm{~Pa} /{ }^{230} \mathrm{Th}$ records and are therefore, not affecting the interpretation, in terms of past circulation changes for all sites. The cores from shallow water depth (DAPC2 and MD95-2037) display trends that present surprising contrasts with the deeper records (Fig. $1 E, 1 D)$. In these shallow cores, the glacial ${ }^{231} \mathrm{~Pa} /{ }^{230} \mathrm{Th}$ are the lowest of the past 20 $\mathrm{kyr}$, and ${ }^{231} \mathrm{~Pa} /{ }^{230} \mathrm{Th}$ increases through the deglaciation, reaching the production ratio of 0.093 during the upper Holocene. The gradual deglacial trends are not interrupted in a major way during the abrupt cold events of Heinrich $1(\mathrm{H} 1)$ and Younger Dryas (YD) that are so strongly imprinted in ${ }^{231} \mathrm{~Pa} /{ }^{230} \mathrm{Th}$ records of the deep cores (Fig. $1 \mathrm{~A}, 1 \mathrm{C}$ ) (McManus et al., 2004; Gherardi et al., 2005). In all cores, the early Holocene is characterized by active renewal rates at all depths (Fig. 1).

The results are summarized in figure $2 \mathrm{~A}$, which shows ${ }^{231} \mathrm{~Pa} /{ }^{230} \mathrm{Th}$ measured in the five cores averaged over five time periods (LGM, H1, BA, YD, late Holocene). While additional cores must be analyzed to better contrast circulation patterns and strength in the eastern and western Atlantic, compilation of the available data already provides a clear picture of the difference in circulation strengths between the Holocene and LGM, and its evolution during deglaciation. These results are consistent with the well-established nutrient proxies (Duplessy et al., 1988; Labeyrie et al., 1992; Curry and Oppo, 2005) but add information on ocean dynamics, which better constrains past changes in the rate of the AMOC.

The Holocene bathymetric profile clearly documents the strength of the AMOC below $3000 \mathrm{~m}$ in the modern ocean. Furthermore, the high ${ }^{231} \mathrm{~Pa} /{ }^{230} \mathrm{Th}$ in the two shallowest cores is consistent with the fact that intermediate North Atlantic water has a longer residence time than NADW (Fig. 2A, 2B) (Broecker and Peng, 1982; Campin et al., 1999). In sharp contrast, the LGM profile shows a dramatic acceleration of the overturning circulation above $3500 \mathrm{~m}$ and a significant but more modest decrease below. This pattern further demonstrates that Glacial North Atlantic Intermediate Water (GNAIW) was largely compensating the weakened deep-water renewal.

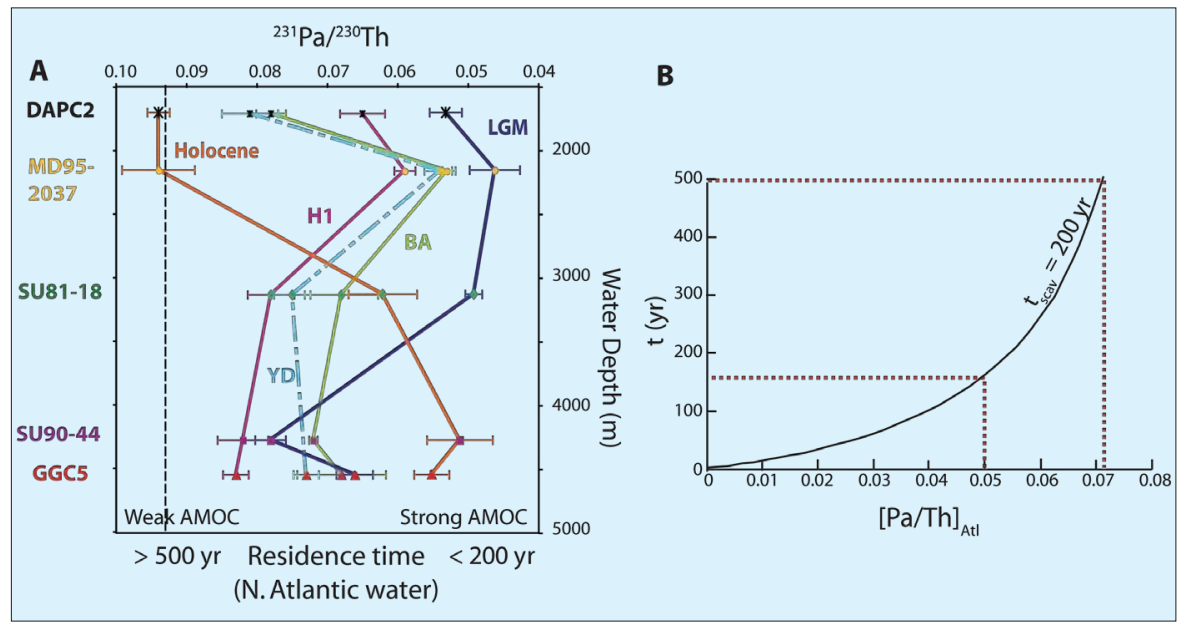

Figure 2: Summary of ${ }^{231} \mathrm{~Pa}{ }^{230}$ Th records presented for different time slices versus water depth. $\boldsymbol{A}$ ) L GM (dark blue), Holocene (orange), Heinrich event 1 (H1; purple), Bølling-Allerød (BA; green), and Younger Dryas (YD; dashed light blue). Note: ${ }^{231} \mathrm{~Pa}{ }^{230}$ Th scale is inverted to show strong MOC on the right hand, and reduced MOC on the left hand side (production ratio represented by the black dash line); $\boldsymbol{B}$ ) Evaluation of North Atlantic water residence time $(t)$ inferred from sedimentary ${ }^{231} \mathrm{~Pa} /{ }^{230} \mathrm{Th}$ ratio, for an estimated Holocene ${ }^{231} \mathrm{~Pa}$ residence time (in response to scavenging) of 200 years $\left(t_{s c a}\right)$. The red dash lines represent the mean ${ }^{231} \mathrm{~Pa} /{ }^{230} \mathrm{Th}$ ratios used to give an estimation of the residence time in figure $2 \mathrm{~A}$ (modified from Yu et al., 1996).

At the beginning of the deglaciation, during $\mathrm{H} 1$ (Fig. 2A, purple profile), the GNAIW shoaled and slowed down, but did not totally shut down. Below 4000 $\mathrm{m},{ }^{231} \mathrm{~Pa} /{ }^{230} \mathrm{Th}$ approaches but does not reach, the production ratio. While the rate of AMOC was clearly at its slowest during that time period, there was still an active, shallow overturning, which is also consistent with nutrient proxy data (Labeyrie et al., 2005).

One of the most surprising results of this new data set is the insight that it provides regarding ocean circulation during the Bølling-Allerød (BA) warm period. While it is widely believed that deepwater circulation during BA was similar to modern circulation, ${ }^{231} \mathrm{~Pa} /{ }^{230} \mathrm{Th}$ clearly indicates that it was intermediate between the full LGM and full Holocene circulation pattern (Fig. 2A, green profile). It is characterized by a notable weakened overturning rate above $2000 \mathrm{~m}$ and a relatively enhanced overturning rate below, compared to the LGM. Notwithstanding this acceleration, deep water overturning during the BA was clearly slower than today.

The following YD cold period was characterized by a slower rate of overturning at all depths than during BA (Fig. $2 A$, dashed light blue profile) (not nearly as pronounced as during $\mathrm{H} 1$ ), with the exception of the shallowest of the cores, which suggests that the sharp slow down of the shallow overturning initiated during the BA did not resume and continued to decrease into the Holocene.

\section{Conclusions}

These results further highlight the potential of sedimentary ${ }^{231} \mathrm{~Pa} /{ }^{230} \mathrm{Th}$ for reconstructing past changes in ocean circulation, and underscore the need for using multiple records to resolve the lateral and depth structure of the AMOC. By compiling the ${ }^{231} \mathrm{~Pa} /{ }^{230} \mathrm{Th}$ ratios in cores at different depths and latitudes from the two basins of the Atlantic, we will be able to improve our reconstruction of past changes in the rate of formation of different water masses and investigate their role in modulating ocean heat-transport during abrupt climatic changes.

\section{Perspectives}

Currently the processes regulating the isotopic equilibration on the settling particles defining the final sedimentary ratio are not fully understood. This work is in progress, as one of the goals of the international research program GEOTRACES. Modeling effort with better representation of particulate processes, is also essential to foster broader application of the proxy.

\section{References}

Yu, E.-F., Francois, R. and Bacon, M., 1996: Similar rates of modern and last-glacial ocean thermohaline circulation inferred from radiochemical data, Nature, 379: 689-694.

McManus, J.F., Francois, R., Gherardi, J.-M., Keigwin, L.D. and BrownLeger S., 2004: Collapse and rapid resumption of Atlantic Meridional Circulation linked to deglacial climate changes, Nature, 428: 834-837.

Gherardi, J.-M., Labeyrie, L., McManus, J.F., Francois, R., Skinner, L.C. and Cortijo, E., 2005: Evidence from the Northeastern Atlantic basin for variability in the rate of the meridional overturning circulation through the last deglaciation, Earth and Planetary Science Letters, 240: $710-723$.

Hall, I.R., Moran, S.B., Zahn, R., Knutz, P.C., Shen, C.-C. and Edwards, R.L., 2006: Accelerated drawdown of meridional overturning in the late-glacial Atlantic triggered by transient pre- $\mathrm{H}$ event freshwater perturbation, Geophysical Research Letters, 33: doi: 10.1029/2006GL026239.

Gherardi J.-M., Labeyrie L., Nave S, Francois R., McManus J.F. and Cortijo E., submitted: Glacial-Interglacial circulation changes inferred from 231Pa/230Th sedimentary record in the North Atlantic region, Paleoceanography.

For full references please consult:

www.pages-igbp.org/products/newsletter/ref2008_1.html 